\title{
CONTEÚDO EXISTENCIAL \\ NAS LÓGICAS ARISTOTÉLICA E CLÁSSICA
}

\section{Diogo Henrique Bispo Dias ${ }^{1}$}

\begin{abstract}
RESUMO
É comumente dito que a lógica aristotélica é incompatível com a lógica clássica, e o motivo para tal é o modo com o qual a lógica aristotélica lida com o conteúdo existencial de suas proposições. Segundo a posição padrão, Aristóteles pressupõe que todas as proposições categoriais têm conteúdo existencial e, sem tal pressuposto, a lógica aristotélica seria inconsistente. O objetivo deste artigo é mostrar, a partir da análise dos textos de Aristóteles, que esta tese é falsa. Argumentaremos que Aristóteles reconhecia a possibilidade de proposições categóricas com termos vazios, e que isso não afeta a consistência interna da lógica aristotélica. Por fim, mostraremos que, ainda assim, a lógica aristotélica continua sendo incompatível com a lógica clássica.
\end{abstract}

Palavras-chave: Conteúdo Existencial. Lógica Aristotélica. Quadrado da Oposição. Lógica Clássica.

\begin{abstract}
It is commonly said that Aristotelian logic is incompatible with classical logic, and the reason for this is the way in which Aristotelian logic deals with the existential import of its propositions. According to the standard position, Aristotle assumes that all categorical propositions have existential import and, without such an assumption, Aristotelian logic would be inconsistent. The purpose of this article is to show, from an analysis of Aristotle's texts, that this thesis is false. We will argue that Aristotle recognized the possibility of categorical propositions with empty terms, and that this does not affect the internal consistency of Aristotelian logic. Finally, we will show that, even so, Aristotelian logic remains incompatible with classical logic.
\end{abstract}

Keywords: Existential Import. Aristotelian Logic. Square of Opposition. Classical Logic.

\footnotetext{
${ }^{1}$ Professor de Filosofia na Universidade Estadual do Norte do Paraná - UENP.

E-mail: diogo.bispo.dias@gmail.com. ORCID: 0000-0002-0601-6850.
} 


\section{Introdução}

É comum se afirmar que a lógica aristotélica é incompatível com a lógica clássica. Fala-se isso, principalmente, por conta do modo com o qual a lógica aristotélica lida com o conteúdo existencial² de suas proposições.

Uma proposição tem conteúdo existencial quando ela pressupõe a existência de algum objeto. Assim, por exemplo, a sentença ${ }^{3}$ "Algum homem é mortal" é geralmente considerada como possuindo conteúdo existencial, visto que ela parece pressupor a existência de, pelo menos, um homem.

A importância do conteúdo existencial para a lógica aristotélica é reconhecida por boa parte da história da filosofia. Ela foi discutida amplamente na Idade Média $^{4}$ e endossada por Leibniz . No entanto, na passagem do século XIX para o século XX, com as primeiras tentativas de uma formalização matemática da lógica, foram evidenciados problemas com esse pressuposto.

Nesse momento, houve um enorme debate não somente sobre a compatibilidade da lógica aristotélica com a lógica matemática que estava surgindo, mas, também, sobre a própria consistência interna da lógica aristotélica. Muitos autores simplesmente defenderam que a lógica aristotélica era inconsistente, e que isso nunca tinha sido percebido ao longo da história da filosofia.

A posição padrão resultante deste debate é que todas as proposições da lógica aristotélica têm conteúdo existencial, e esta lógica só é consistente se aceitarmos este pressuposto. Por outro lado, como a lógica clássica não aceita este pressuposto, estas duas lógicas são, portanto, incompatíveis.

Nesse sentido, o objetivo desse texto é apresentar brevemente esse debate e mostrar que ainda que essas duas lógicas sejam, de fato, incompatíveis, o motivo desta incompatibilidade é mal interpretado por boa parte da literatura. Defenderemos, também, que há uma interpretação natural, e fiel a várias passagens dos textos de Aristóteles, que permite concluir que nem toda propo-

\footnotetext{
${ }^{2}$ Em inglês, usa-se a expressão "existential import". Também seria possível traduzi-la para o português como "importe existencial". Usamos "conteúdo existencial" para manter a terminologia presente nos principais manuais de lógica em português, como COPI (1978), e MORTARI (2017).

${ }^{3}$ Usaremos sentença e proposição como sinônimas.

${ }^{4}$ Cf. MOODY (1953).

${ }^{5}$ Cf. KATTSOFF (1934).
} 
sição na lógica aristotélica pressupunha conteúdo existencial ${ }^{6}$, e que esta interpretação torna esta lógica internamente consistente.

\section{Lógica Aristotélica}

Comecemos por alguns comentários gerais sobre a lógica aristotélica. Esta tem como noção central o conceito de dedução. Assim,

Uma dedução é um discurso (logos) no qual, certas coisas sendo supostas, algo diferente das coisas supostas segue-se por necessidade. (ARISTÓTELES, Analíticos Anteriores I, 24b19-20)7.

As coisas supostas são o que chamamos de premissas, e aquilo diferente que se segue destas é chamado de conclusão. A noção de necessidade presente nesta definição corresponde, em linhas gerais, à noção moderna de validade: um argumento é válido quando é impossível que suas premissas sejam verdadeiras, e a conclusão falsa. Ou ainda: a conclusão segue por necessidade das premissas se é impossível para a conclusão ser falsa quando as premissas são verdadeiras.

Nesta definição de dedução, já é possível identificar diferenças importantes com relação à noção moderna de validade. Dois tipos de argumentos permitidos na lógica clássica são, de princípio, excluídos da lógica aristotélica, a saber:

I. argumentos em que a premissa é igual à conclusão;

II. argumentos com uma única premissa.

Além disso, a lógica aristotélica lida somente com argumentos na forma chamada de silogismo categórico. Isto significa que as sentenças que fazem parte do silogismo são sentenças declarativas, ou seja, sentenças que podem ser consideradas verdadeiras ou falsas, nas seguintes formas:

\footnotetext{
${ }^{6}$ Além disso, o presente artigo se mostra importante, pois o debate sobre o papel do conteúdo existencial na lógica aristotélica é majoritariamente feito em língua inglesa.

${ }^{7}$ Todas as traduções para o português são do autor.
} 
Sentença do tipo A: Todo S é P;

Sentença do tipo E: Nenhum S é P;

Sentença do tipo I: Algum S é P;

Sentença do tipo O: Algum S não é P. ${ }^{8}$

Aristóteles defende que toda asserção deve afirmar ou negar a atribuição de um único predicado a um único sujeito. Ou seja, a lógica aristotélica não permite, nos silogismos, sentenças conjuntivas ou disjuntivas, por exemplo. Podemos ver, também, que Aristóteles não considera negação como uma sentença composta.

Ainda assim, essas diferenças não são suficientes para afirmar que a lógica aristotélica é incompatível com a lógica clássica. Aquela poderia constituir um fragmento desta, e simplesmente diríamos que a lógica clássica aumentou o escopo de aplicação da lógica aristotélica. Para evidenciar a raiz dessa incompatibilidade, vejamos algumas relações entre proposições na lógica aristotélica:

I. Duas sentenças são contraditórias se é impossível que ambas sejam falsas, e ambas sejam verdadeiras.

II. Duas sentenças são contrárias se é impossível que ambas sejam verdadeiras, mas é possível que ambas sejam falsas9.

III. Duas sentenças são subcontrárias se é impossível que ambas sejam falsas, mas é possível que sejam verdadeiras.

IV. Duas sentenças são chamadas de subalterna e superalterna, respectivamente, quando a verdade da superalterna implica a verdade da subalterna, e a falsidade da subalterna implica na falsidade da superalterna.

\footnotetext{
${ }^{8}$ Existe um debate acerca da presença - ou não - de sentenças singulares do tipo "Sócrates é mortal" na lógica aristotélica. As teses defendidas neste artigo são independentes do resultado desse debate. Sobre essa discussão, Cf. READ (2015).

${ }^{9}$ Para ver a formulação precisa dada por Aristóteles para as noções de contraditoriedade e contrariedade, Cf. ARISTÓTELES, Da Interpretação, 17b16-20, e 17b20-26, respectivamente.
} 
Aristóteles afirma que $\mathbf{A}$ e $\mathbf{O}$ são contraditórias, que $\mathbf{E}$ e I são contraditórias $^{10}$, e que A e $\mathbf{E}$ são contrárias ${ }^{11}$. A partir destas afirmações, podemos inferir outras relações entre as sentenças. Para ver que I e $\mathbf{O}$ são subcontrárias, suponha que I é falsa. Logo, E é verdadeira. A contrária de $\mathbf{E}, \mathbf{A}$, é falsa. E sua contraditória, $\mathbf{O}$, é verdadeira. Assim, I e $\mathbf{O}$ não podem ambas ser falsas. Por outro lado, é possível que tanto I quanto $\mathbf{O}$ sejam verdadeiras. Portanto, I e $\mathbf{O}$ são subcontrárias.

Por fim, se A é verdadeira, então I também o é. E, se I é falsa, isso significa que A também é falsa. Logo, uma sentença A é superalterna de sua sentença $\mathbf{I}$ correspondente ${ }^{12}$, e essa sentença $\mathbf{I}$ é subalterna à sentença $\mathbf{A}$ correspondente. Um raciocínio análogo mostra que a relação de subalternação também se aplica a sentenças do Tipo $\mathbf{E}$ e $\mathbf{O}$.

Essas relações podem ser apresentadas graficamente através do chamado Quadrado da Oposição:

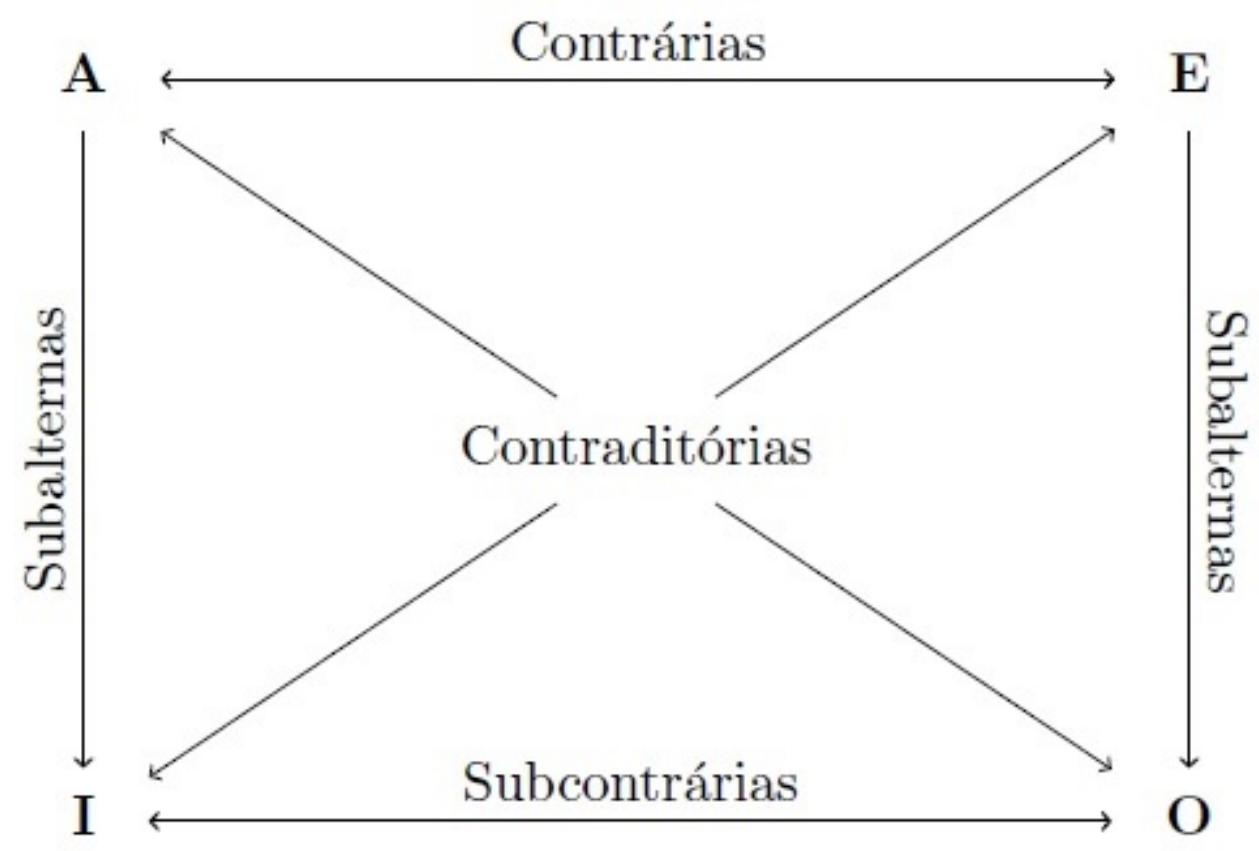

Esse diagrama não foi formulado por Aristóteles e sua primeira aparição conhecida data do século II d.C, na obra de Apuleio de Madaura ${ }^{13}$.

\footnotetext{
${ }^{10}$ Cf. ARISTÓTELES, Da Interpretação, 17b18-19.

${ }^{11}$ Cf. ARISTÓTELES, Da Interpretação. 17b6-8.

12 Isto é, de uma sentença I com mesmo sujeito e predicado da sentença $\mathbf{A}$.

${ }^{13}$ Cf. LONDEY e JOHANSON (1978), pp. 108-12.
} 
Além das relações acima, Aristóteles afirma que $\mathbf{E}$ e I têm conversão simples $^{14}$, isto é, "Nenhum $\mathrm{S}$ é P" é equivalente em valor de verdade a "Nenhum P é S" e "Algum S é P" é equivalente em valor de verdade a "Algum $P$ é S”.

Assim, chamaremos de lógica aristotélica as relações constituintes do Quadrado da Oposição, a tese que de vale a conversão simples de E e I e a silogística aristotélica.

\section{Críticas à lógica aristotélica}

No início do século XX, com o desenvolvimento do que hoje é chamado de lógica clássica, vários autores começaram a apontar inconsistências na lógica aristotélica ${ }^{15}$. Uma das principais críticas, que se tornou padrão a partir da análise de Łukasiewicz $^{16}$ (1951), é a de que a lógica aristotélica não consegue lidar com a presença de termos vazios.

$\mathrm{O}$ argumento padrão apresentado é o seguinte: suponha que S seja um termo vazio. Logo, a sentença "Algum S é P" é falsa. Sua contraditória, "Nenhum S é P", portanto, é verdadeira. Assim, sua subalterna, "Algum S não é P” deve ser verdadeira. Mas, por hipótese inicial, S é um termo vazio. Algo está errado, pois a sentença “Algum S não é P” parece pressupor que existe, ao menos, um $\mathrm{S}$.

Nessa situação, parece que praticamente todas as relações no quadrado das oposições se perdem. Se S é vazio, I e $\mathbf{O}$ podem ambas ser falsas, portanto, não são sentenças subcontrárias. Mas, neste caso, suas contraditórias, A e E, podem ser ambas verdadeiras. Perdemos, portanto, a relação de contrariedade também. Como I e $\mathbf{O}$ podem ser ambas falsas, e $\mathbf{A}$ e E, verdadeiras, perdem-se também as relações de subalternação.

Esses argumentos dependem de dois pressupostos:

\footnotetext{
${ }^{14}$ Cf. ARISTÓTELES, Analíticos Anteriores, 25a4-9.

${ }^{15}$ Cf. NORTHROP (1928), ŁUKASIEWICZ (1957), SMITH (2019), MIGNUCCI (2007), KEYNES (1887), ROSE (1968).

${ }^{16}$ Łukasiewicz é um dos precursores das lógicas não-clássicas, sendo o criador das primeiras lógicas multivaloradas (que admitem valores de verdade além de Verdadeiro e Falso), e responsável por escrever um artigo importante com a primeira crítica elaborada ao princípio de não-contradição. Cf. ŁUKASIEWICZ (2005).
} 
I. É permitido o uso de termos vazios;

II. Proposições particulares têm conteúdo existencial, isto é, elas pressupõem a existência de um indivíduo que instancia seu sujeito. Assim, por exemplo, a sentença "Algum unicórnio é verde" é verdadeira quando existe ao menos um unicórnio, e este unicórnio é verde.

A partir desse tipo de raciocínio, Kneale e Kneale concluem que a lógica aristotélica "pode ser justificada, como um todo, se supusermos que ela estava lidando somente com termos que têm aplicação" (KNEALE \& KNEALE, 1962, p. 59) ${ }^{17}$, isto é, com termos que têm conteúdo existencial.

Mignucci argumenta que, além do termo sujeito, o termo predicado também deve ser não-vazio:

De um ponto de vista técnico, para justificar a lógica aristotélica, em geral, precisamos evitar termos vazios não somente na posição do sujeito, mas, também, na posição do predicado. É verdade que, para evitar os contraexemplos ao quadrado da oposição é suficiente impor a exigência de que os sujeitos das proposições sejam termos não-vazios. Mas também é verdadeiro que Aristóteles também aceitava a conversão das proposições. [...] Para aceitar essas teses, deve-se conceder que não somente sujeitos, mas, também, predicados devem ser termos não-vazios (MIGNUCCI, 2007, p. 137) ${ }^{18}$.

Jacobs afirma que os complementos ${ }^{19}$ de $\mathrm{S}$ e $\mathrm{P}$ também devem ser não-vazios:

Para permitir todas as inferências imediatas de Aristóteles, devemos assumir que tanto os termos $\mathrm{S}$ e $\mathrm{P}$, bem como seus complementos não-S e não-P são bem sucedidos em denotar (JACOBS, 1980, p. 419$)^{20}$.

\footnotetext{
17 "[it] can be justified as a whole, if we suppose that [it] was dealing only with terms that have application".

18 "From a technical point of view, to justify Aristotle's logic in general we need to avoid empty terms not only in a subjective but also in a predicative position. It is true that to avoid the counterexamples to the square of opposition it is sufficient to impose the requirement that the subjects of the propositions be not empty terms. But is also true that Aristotle accepted also conversion of propositions. [...] To accept these views one must concede that not only subjects but also predicates must be non-empty terms".

${ }^{19} \mathrm{O}$ complemento de uma classe é a coleção de todas as coisas que não pertencem a esta classe. Assim, o complemento da classe dos mortais é a classe de todas as coisas que são não-mortais.

20 "In order to allow all of Aristotle's immediate inferences we must assume that both the terms $\mathrm{S}$ and $\mathrm{P}$ and their complements non-S and non-P successfully denote".
} 
A partir destas considerações, tornou-se padrão aceitar que a lógica aristotélica só é consistente se todos os termos de todas as sentenças tiverem conteúdo existencial. Além disso, é comum dizer que essa pressuposição não era reconhecida por Aristóteles ou pelos medievais e que, portanto, todos estes faziam uso de uma lógica inconsistente.

Visto que a lógica aristotélica foi mantida por praticamente dois mil anos, é estranho pensar que tal falha passou incólume. Haveria outra explicação disponível? Mostraremos que sim. Como ficará claro, defenderemos que o quadrado da oposição é coerente com a presença de termos vazios. A partir da análise do próprio texto de Aristóteles, veremos que proposições negativas, $\mathbf{O}$ e E, não têm conteúdo existencial. Sendo assim, proposições desses tipos são verdadeiras por vacuidade se o sujeito é vazio.

Começaremos investigando o caso das sentenças afirmativas. A verdade da sentença "Algum homem é mortal" pressupõe, naturalmente, a existência de um homem. Portanto, é consenso que sentenças do tipo I têm conteúdo existencial.

Vejamos o caso de proposições afirmativas universais. Para tal, considere o seguinte silogismo ${ }^{21}$ :

\section{Todo C é B}

Todo C é A

\section{Algum A é B}

Se considerarmos que sentenças do tipo A não têm conteúdo existencial, então o argumento é inválido. Mas como Aristóteles defende que o argumento é válido ${ }^{22}$, sabemos que ele considera $\mathbf{A}$ como possuindo conteúdo existencial. Além disso, como a verdade de A implica na verdade de I, e I tem conteúdo existencial, A também deve ter.

Portanto, estabelecemos que as proposições categoriais afirmativas, particulares e universais, pressupõem conteúdo existencial. Até aqui, há um consenso na literatura. O ponto de discórdia está na interpretação da sentença

\footnotetext{
${ }^{21}$ Esta forma de silogismo é denominada, pelos medievais, de Darapti.

${ }^{22}$ Cf. ARISTÓTELES, Analíticos Anteriores I, 39a15-18.
} 
particular negativa. A literatura padrão defende que Aristóteles aceitava que proposições do tipo $\mathbf{O}$ também têm conteúdo existencial. Mostraremos que esta tese é falsa ${ }^{23}$.

Em primeiro lugar, é fácil ver que Aristóteles reconhece a existência de proposições com termos vazios, e a possibilidade de determinar o valor de verdade desse tipo de proposição ${ }^{24}$. Nas Categorias, Aristóteles afirma que:

Com uma afirmação e negação, uma sempre será falsa e a outra verdadeira, quer [o sujeito] exista ou não. Pois tome "Sócrates é doente" e "Sócrates não é doente": se ele é doente, é claro que uma ou outra dessas sentenças será verdadeira ou falsa, e igualmente se ele não existe; pois, se ele não existe, "ele é doente" é falsa, mas "ele não é doente" é verdadeira. (ARISTÓTELES, Categorias, 13b2327).

Aristóteles também frequentemente faz uso de termos vazios, como bode-cervo e centauros ${ }^{25}$. O próximo passo é verificar que algumas proposições categoriais também podem ter termos vazios. $\mathrm{O}$ segredo para entender que proposições negativas particulares não tem conteúdo existencial é reconhecer que, em Aristóteles, a forma $\mathbf{O}$ não é a usual “Algum $\mathrm{S}$ não é P”, mas, sim, "Nem todo S é P". Como aponta Wedin ${ }^{26}$, isto está no próprio texto de Aristóteles:

Chamo uma afirmação e uma negação de opostos contraditórios quando aquilo que uma significa universalmente, a outra significa não-universalmente. Exemplo: 'todo homem é bran-

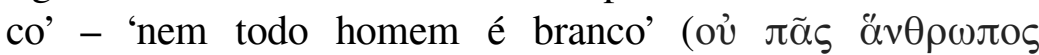
$\lambda \varepsilon v \kappa o ́ s)^{27}$, 'nenhum homem é branco' - 'algum homem é branco' (ARISTÓTELES, Da Interpretação, 17b17-19)

\footnotetext{
${ }^{23}$ Esta tese está presente em THOMPSON (1953), MOODY (1953), PRIOR (1962), WEDIN (1978, 1990), PARSONS (2017) e READ (2015).

${ }^{24}$ Este argumento foi apresentado por PRIOR (1962), e desenvolvido por WEDIN (1978).

${ }^{25}$ Cf. ARISTÓTELES, Analíticos Anteriores I, 49a24 e Analíticos Posteriores I, 89b32, respectivamente.

${ }^{26}$ Cf. WEDIN (1990). Essa interpretação da sentença de tipo O já está em MOODY (1953), mas este estava simplesmente buscando formular uma interpretação coerente da lógica aristotélica, sem se preocupar se o próprio Aristóteles defenderia esta posição.

${ }^{27}$ Aqui, coloco a expressão original em grego para enfatizar a escolha por traduzir como "Nem todo homem é branco". O texto grego utilizado é ARISTÓTELES (1962). Agradeço à Amarilis Ferreira pela ajuda com o texto original.
} 
Vemos o mesmo em: “o oposto de 'todo homem é branco' é 'nem todo

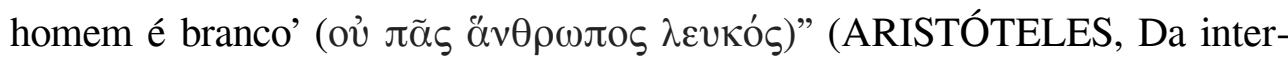
pretação, 18a5).

A formulação "Nem todo S é P" deriva da tradução do Aristóteles para o latim, feita por Boécio, que foi uma dos principais responsáveis pela popularização da obra de Aristóteles no ocidente. No entanto, nos seus próprios comentários à obra de Aristóteles, Boécio usa a forma "Algum $\mathrm{S}$ não é P”. Parsons ${ }^{28}$ conjectura que isso se deu pois Boécio considerava que as duas formas são equivalentes em latim. De qualquer modo, a leitura dos comentários de Boécio se popularizou, e virou a forma padrão de ler proposições do tipo $\mathbf{O}^{29}$.

É relevante apontar que os comentários de Al-Farabi ${ }^{30}$ sobre os Analíticos Anteriores apresenta frequentemente a proposição de tipo $\mathbf{O}$ como "Nem todo X é E”. Curiosamente, o tradutor desta obra para o inglês escolhe traduzir este trecho como "Some $\mathrm{X}$ is not $\mathrm{E}$ [Algum $\mathrm{X}$ não é E]", e apenas reconhece em uma nota que não está sendo fiel ao texto original ${ }^{31}$.

Os Analíticos Anteriores oferecem outra evidência da tese de que sentenças categoriais particulares negativas não têm conteúdo existencial. Nessa obra, Aristóteles também expressa sentenças do tipo $\mathbf{O}$ como "B não pertence

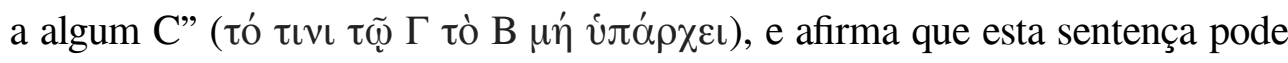
ser verdadeira em duas situações, "se [B] não pertence a nenhum [C], e se [B] não pertence a todo [C]” (ARISTÓTELES, Analíticos Anteriores I, 26b1517). $O$ ponto central, aqui, é que "é verdade que $M$ não pertence a algum $O$ mesmo se ele não pertence a nenhum O” (ARISTOTELES, Analíticos Anteriores I, 27b21-22).

A partir dessas considerações, podemos concluir que proposições do tipo $\mathbf{O}$ não têm conteúdo existencial. O último parágrafo também nos mostra que uma proposição do tipo $\mathbf{E}$ é verdadeira quando o sujeito é vazio, pois a se-

\footnotetext{
${ }^{28}$ Cf. PARSONS (2017).

${ }^{29}$ É curioso notar que, já no século XII, Abelardo criticava a formulação da sentença $\mathbf{O}$ presente nos comentário de Boécio. Cf. PARSONS (2017), nota 8.

${ }^{30}$ Al-Farabi é um filósofo Árabe do século IX. Cf. RESCHER (1963).

${ }^{31}$ Cf. RESCHER (1963), p. 61, nota 9.
} 
gunda condição de verdade de "B não pertence a algum C", isto é, quando B pertence nenhum $\mathrm{C}$, é a mesma condição de verdade da proposição universal negativa "Nenhum B é C".

Com essa leitura, considere que $\mathrm{S}$ é um termo vazio. Sendo assim, a sentença “Algum S é P” é falsa. Logo, "Nenhum S é P” é verdadeira e, portanto, "Nem todo S é P" é verdadeira e "Todo S é P" é falsa. Por outro lado, Se “Todo S é P" é verdadeira, então "Algum S é P" é verdadeira, pois proposições afirmativas têm conteúdo existencial. Logo, "Nem todo S é P" é falso, e, portanto, "Nenhum S é P" também é falso. Assim, temos todas as relações do quadrado preservadas.

\section{Contraposição e obversão}

Acima, consideramos como Lógica Aristotélica o Quadrado da Oposição, a silogística, mais a conversão simples. No entanto, há outros princípios que são geralmente considerados como parte desta lógica, a saber: contraposição e obversão. A contraposição consiste em substituir, em proposições categoriais do tipo A e $\mathbf{O}$, o sujeito da proposição com o complemento do seu predicado, e substituir o predicado com o complemento do seu sujeito. Assim, a contrapositiva de "Todo homem é mortal" é "Todo não-mortal é nãohomem". Obversão, por sua vez, trata-se da operação de mudar, em qualquer proposição categorial, a qualidade da proposição (de afirmativa para negativa, ou vice-versa), e trocar o predicado da proposição pelo complemento do predicado. Deste modo, a obsersão de “Todo homem é mortal” é Nenhum homem é não-mortal”.

O problema é que, como aponta Parsons ${ }^{32}$, a aceitação destes princípios está em conflito com a tese de que a lógica aristotélica é capaz de lidar com termos vazios. Para ver isto, suponha que "Todo homem é um ser" é verdadeira. Sua contrapositiva é "Todo não-ser é um não-homem”. Como sentenças do tipo A têm conteúdo existencial, e o termo "não-ser" é vazio, a sentença "Todo não-ser é um não-homem" é falsa. Logo, partimos de uma sentença verdadeira e, através da contraposição, chegamos a uma sentença falsa.

\footnotetext{
${ }^{32}$ Cf. PARSONS (2017).
} 
Este exemplo foi apresentado por Buridan para defender a ilegitimidade da contraposição. Ainda que, no século XII, vários autores aceitavam esta inferência ${ }^{33}$, no século XIV, o problema apontado por Buridan era amplamente conhecido, e a contraposição era considerada inválida, a não ser quando os termos da proposição não eram vazios.

Com respeito à obversão, temos uma situação análoga. Suponha que "nenhum marciano é verde" é verdadeira, e que não existem marcianos. Logo, "todo marciano é não-verde" é falsa. Portanto, a obversão de $\mathbf{E}$ para A é ilegítima. Da mesma forma, se "nem todo marciano é verde" é verdadeira, e não existem marcianos, a sentença "algum marciano é não-verde" é falsa. Logo, a obversão de $\mathbf{O}$ para I é inválida.

É importante notar que o próprio Aristóteles não reconhece obversão como um procedimento geral. No entanto, ele reconhece algumas aplicações particulares:

'Nenhum homem é justo' segue-se de 'todo homem é não-justo', en-

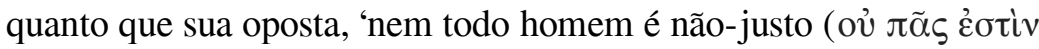

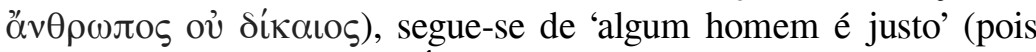
deve existir um) ${ }^{34}$ (ARISTÓTELES, Da Interpretação, 20a19-21)

Portanto, a obversão funciona para as sentenças de tipo A e I, isto é, sentenças afirmativas. Church afirma que Aristóteles nunca apresenta obversão de uma sentença negativa ${ }^{35}$. A partir das considerações acima, agora estamos em uma posição de entender esta ausência. Aristóteles não defende a obversão de proposições negativas, pois essa inferência não vale na presença de proposições sem conteúdo existencial.

Alguns medievais dos séculos XII e XIII defendiam a legitimidade da obversão, e outros a rejeitavam. No século XIV, novamente, era claro que a obversão de sentenças negativas só valia quando os termos da proposição não eram vazios ${ }^{36}$.

\footnotetext{
${ }^{33}$ Cf. PARSONS (2017).

${ }^{34}$ Note que, aqui, o conteúdo existencial da sentença de tipo I é explícito.

${ }^{35}$ Cf. CHURCH (1965), p. 419.

${ }^{36}$ Cf. PARSONS (2017), notas 16 e 17.
} 


\section{Objeções}

Alguns autores rejeitam essa solução proposta. Priest ${ }^{37}$ (2003), por exemplo, diz que aceitar que a sentença "Algum S não é P" não tem conteúdo existencial é estranho ${ }^{38}$. Ademais, ele reconhece que essa aceitação invalidaria a obversão, pois podemos passar de "Nenhum A é B" para "Todo A é não-B". Assim, poderíamos inferir conteúdo existencial de uma proposição sem conteúdo existencial.

A primeira objeção é adequadamente dissolvida quando reconhecemos que a melhor forma de formular uma sentença do tipo $\mathbf{O}$ é "Nem todo $\mathrm{S}$ é P". Ainda que seja estranho aceitar que a proposição "Algum marciano não é verde" possa ser verdadeira se não existe nenhum marciano, o mesmo não acontece se considerarmos a proposição "Nem todo marciano é verde". Esta sentença só será falsa se todos os marcianos forem verdes. Assim, se não existirem marcianos, "nem todo marciano é verde" é verdadeira por vacuidade.

Por sua vez, a segunda objeção é adequadamente rejeitada a partir dos comentários sobre obversão da seção anterior. Priest está correto em afirmar que essa interpretação invalidaria a obversão de $\mathbf{E}$ para $\mathbf{A}$. O erro é não reconhecer que tanto Aristóteles, quanto os principais lógicos medievais sabiam disso e, exatamente por isso, ou a obversão não era defendida, ou era explicitado que ela dependia da postulação de conteúdo existencial das sentenças envolvidas.

Em suma, sentenças afirmativas contêm conteúdo existencial, ao passo que sentenças negativas não contêm. O argumento contra o quadrado da oposição não foi levantado antes do século XIX, pois essa era uma visão padrão. Por exemplo, Ockham afirma que:

Em proposições afirmativas, sempre se declara que um termo supõe algo. Logo, se ele não supõe nada, a proposição é falsa. No entanto, em proposições negativas, a declaração é de que ou o termo não supõe nada, ou ele supõe algo sobre o qual o predicado é verdadeiramente negado. Assim, uma proposição negativa tem duas causas de verdade (OCKHAM, 1974, p. 206) ${ }^{39}$.

${ }^{37}$ Cf. PRIEST (2003).

38 O mesmo ponto é defendido por MIGNUCCI (2007), pp. 127-8.

39 "In affirmative propositions a term is always asserted to supposit for something. Thus, if it supposits for nothing the proposition is false. However, in negative propositions the asserti- 
Essa mesma posição é reafirmada, no século XIV, por Buridan, Ockham e Paulo de Venice.

No século XIX, os principais livros de lógica de língua inglesa incluíam contraposição e obversão como inferências legítimas, mas sem nenhuma discussão profunda sobre o papel do conteúdo existencial ${ }^{40}$. As obras de Łukasiewicz (1951) e de Kneale e Kneale (1962) atribuíram a Aristóteles essa visão da lógica desenvolvida ao longo do século XIX, que se torna inconsistente na presença de termos vazios.

No entanto, como vimos, esta crítica não se aplica ao que chamamos de lógica aristótélica, isto é, à lógica explicitamente endossada por Aristóteles. Alguns autores alertavam para essa confusão, reconhecendo que esta acusação de inconsistência à lógica aristotélica "dependia do pressuposto, não feito na lógica medieval, de que o conteúdo existencial deve ser atribuído às formas negativas assim como às afirmativas" (MOODY, 1953, p. 53) ${ }^{41}$. Do mesmo modo, Ashworth lamenta que

A maioria dos lógicos depois da terceira década do século XVI parou de discutir esses assuntos [i.e., conteúdo existencial das proposições], com o resultado de que os leitores modernos tendem a pensar que a lógica tradicional carece de uma sofisticação que ela, de fato, possui (ASHWORTH, 1973, p. 147) ${ }^{42}$.

\section{Versão Moderna do Quadrado:}

Chegamos à conclusão de que a interpretação adequada da lógica aristotélica é afirmar que proposições A e I têm conteúdo existencial, mas proposições E e O, não. Veremos, agora, que, mesmo com essa interpretação, a lógica aristotélica continua incompatível com a lógica clássica.

As proposições categóricas da lógica aristotélica são formalizadas, na lógica clássica, como:

on is either that the term does not supposit for something or that it supposits for something of which the predicate is truly denied. Thus a negative proposition has two causes of truth".

${ }^{40}$ Cf. PARSONS (2017), nota 25.

41 "rest[s] on the assumption, not made in mediaeval logic, that existential import is to be assigned to the negative forms as well as the affirmative ones".

42 "The vast majority of logicians after the third decade of the 16th century ceased to discuss these matters, with the result that modern readers tend to think of traditional logic as lacking a sophistication which it did indeed possess". 
Perspectiva Filosófica, vol. 47, n. 2, 2020

$\begin{array}{ll}\text { Todo S é P } & \forall \mathrm{x}(\mathrm{Sx} \rightarrow \mathrm{Px}) \\ \text { Nenhum S é P } & \forall \mathrm{x}(\mathrm{Sx} \rightarrow \neg \mathrm{Px}) \\ \text { Algum S é P } & \exists \mathrm{x}(\mathrm{Sx} \& \mathrm{Px}) \\ \text { Algum S não é P } & \exists \mathrm{x}(\mathrm{Sx} \& \neg \mathrm{Px})\end{array}$

Para ver que as duas lógicas são incompatíveis, basta notar que o silogismo Darapti:

\section{Todo C é B}

Todo Cé A

Algum A é B

é válido na lógica aristotélica, mas inválido na lógica clássica. O motivo para isso é óbvio. Todas as sentenças afirmativas têm conteúdo existencial na lógica aristotélica. A lógica clássica, por sua vez, relaciona o conteúdo existencial com a quantidade das proposições categoriais, e não com a qualidade. Assim, proposições universais não têm conteúdo existencial, e proposições particulares têm. Sendo assim, o silogismo acima se torna inválido quando permitimos que $\mathrm{C}$ seja vazio.

Com essa reformulação, as relações do quadrado das oposições praticamente somem:

A

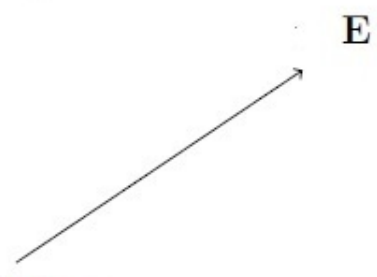

\section{Contraditórias}
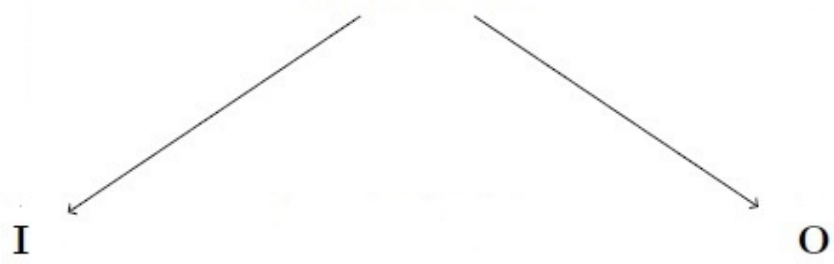
Suponha que $\mathrm{S}$ é vazio. Assim, A e E são ambas verdadeiras e, portanto, não são contrárias. Por sua vez, I e O, por terem conteúdo existencial na lógica clássica, podem ser ambas falsas e, logo, não são subcontrárias. Como A e $\mathbf{E}$ podem ser verdadeiras, e I e $\mathbf{O}$, falsas, também perdemos as relações de subalternação. Portanto, considerando que apenas as sentenças particulares têm conteúdo existencial, as únicas relações que sobram no quadrado moderno são as de contraditoriedade. Segundo Church, essa visão da lógica aristotélica surgiu no final do século XIX, nas obras de Cayley - ainda que implicitamente -, Brentano, Peirce e Venn ${ }^{43}$.

É curioso que esta interpretação seja frequentemente chamada de "interpretação booleana", dando a impressão de que teria sido formulada por George Boole. De fato, o trabalho de Boole forneceu o aparato formal no qual o papel do conteúdo existencial das proposições poderia ser melhor explicitado. No entanto, Boole nunca levou a cabo tal explicitação, tampouco estava interessado em comparar sua formulação com a obra de Aristóteles. Em particular, Boole aceitava a inferência de uma proposição do tipo A para uma proposição do tipo $\mathbf{I}^{44}$ e, portanto, aceitava que proposições universais tinham conteúdo existencial. A discussão sobre o conteúdo existencial das proposições categóricas e a tese de que apenas sentenças particulares continham tal conteúdo só se tornaram explícitas com Brentano e, principalmente, com a formulação dos diagramas de Venn. Por esse motivo, Prior chama esta interpretação de "interpretação de Brentano-Venn"

Logo, a lógica aristotélica não é compatível com a lógica clássica. Sua compatibilidade só se torna possível ao mudarmos o pressuposto aristotélico fundamental de que o conteúdo existencial é determinado pela qualidade das proposições categóricas, e não por sua quantidade.

\footnotetext{
${ }^{43}$ Cf. CHURCH (1965), p. 422.

${ }^{44}$ Cf. BOOLE (1847), p. 38. Para uma análise da lógica algébrica de Boole, evidenciando que esta lógica ainda pressupunha que proposições universais contêm conteúdo existencial, cf. VALENCIA (2004).

${ }^{45}$ Cf. PRIOR (1976), p. 123. Para uma análise do desenvolvimento do debate sobre conteúdo existencial no século XIX, cf. WU (1969).
} 


\section{Conclusão}

Esse artigo apresentou uma interpretação minoritária da lógica aristotélica. Uma das consequências do não reconhecimento desse debate acerca do conteúdo existencial é que os principais livros didáticos de lógica simplesmente se limitam a repetir a tese que se consolidou, a partir do século XIX, de que a lógica aristotélica não é capaz de lidar com termos vazios. Por exemplo, Hausman, Kahane e Tidman afirmam que "a lógica silogística tradicionalmente depende do pressuposto de que todas as proposições [que figuram nos silogismos] têm conteúdo existencial" (HAUSMAN, KAHANE \& TIDMAN, 2007, p. 319) ${ }^{46}$. Mortari repete a tese de que

O conflito [entre as lógicas aristotélica e clássica] tem a ver com o fato de que, do ponto de vista contemporâneo, proposições universais não têm conteúdo existencial, ao contrário das particulares. Para a interpretação tradicional dos silogismos, contudo, proposições universais também tinham conteúdo existencial ${ }^{47}$. (MORTARI, 2017, p. 521)

Copi, ademais, enfatiza que é preciso estender essa exigência aos complementos dos termos:

Se fizermos a pressuposição geral de que todas as classes designadas pelos nossos termos (e seus complementos) têm membros, então [...] a totalidade das relações estabelecidas no Quadro de Oposição tradicional mantém-se de pé (COPI, 1978, p. 157).

Como vimos, nenhuma destas teses está em Aristóteles, e as implicações da aceitação ou rejeição de termos vazios foi amplamente reconhecida e discutida pelos lógicos medievais.

Assim, esse artigo pretende contribuir, por um lado, para uma melhor compreensão dos pressupostos filosóficos envolvidos na lógica aristotélica, e o modo como esses pressupostos foram interpretados ao longo da história. Por outro lado, esperamos que este tipo de investigação mostre o papel fundamental dos aspectos filosóficos envolvidos na formulação de uma lógica, e de como esses aspectos influenciam em questões que geralmente são consideradas

\footnotetext{
46 "Syllogistic logic traditionally rested on the assumption that all the propositions to be dealt with do have existential import".

${ }^{47} \mathrm{O}$ autor também pressupõe que proposições particulares na lógica aristotélica têm conteúdo existencial.
} 
meramente técnicas, como, por exemplo, determinar a validade de um argumento $^{48}$.

\section{Referências}

ARISTOTLE. The Categories. On Interpretation. Cambridge: Harvard University Press, 1962.

ASHWORTH, E. J. "Existential assumptions in late medieval logic". American Philosophical Quarterly, 10, 1973, pp. 141-147.

BARNES, J. The Complete Work of Aristotle. Vol. 1. Princeton: Princeton University Press, 1991.

BOOLE, G. The Mathematical Analysis of Logic. Cambridge: Cambridge University Press, 1847.

$\mathrm{CHURCH}, \mathrm{A}$. "The History of the Question of Existential Import of Categorical Propositions". In: BAR-HILLEL, B. (ed.). Logic, Methodology, and Philosophy of Science (Proceedings of the 1964 International Congress). Amsterdam: North-Holland, pp. 417-24.

COPI, I. Introdução à Lógica. 2ª Edição. São Paulo: Mestre Jou, 1978.

HAUSMAN, A.; KAHANE, H.; TIDMAN, P. Logic and Philosophy. Tenth Edition. Belmont: Thomson Wadsworth, 2007.

KATTSOFF, L. "Concerning the Validity of Aristotelian Logic". Philosophy of Science. Vol. 1, no. 2, 1934, pp. 149-162.

KEYNES, J. N. Studies and Exercises in Formal Logic. Cambridge: McMillan and Co., 1887.

ŁUKASIEWICZ, J. Aristotle's Syllogistic from the Standpoint of Modern Logic. Oxford: Clarendon Press, 1951.

. "Sobre a Lei da Contradição em Aristóteles". In: ZIN-

GANO, M. (org.). Sobre a Metafísica de Aristóteles. São Paulo: Odysseus, 2005, pp. 1-24.

MATES, B. Elementary Logic. New York: Oxford University Press, 1972.

MIGNUCCI, M. "Aristotle on the Existential Import of Propositions". Phronesis, Vol. 52, no 2, 2007, pp, 121-138.

${ }^{48}$ Gostaríamos de agradecer o(a) parecerista anônimo(a) pela leitura cuidadosa do texto, bem como pelas valiosas sugestões. 
MOODY, E. A. Truth and Consequence in Mediaeval Logic. Amsterdam: North-Holland, 1953.

MORTARI, C. A.; Introdução à Lógica. 2ª edição. São Paulo: Unesp, 2017.

NORTHROP, F. S. C. "An Internal Inconsistency in Aristotelian Logic". The Monist. Vol. 38, no 2, 1928, pp. 193-210.

OCKHAM, W. Summa Logicae: Theory of Terms. Part I. Indiana: University of Notre Dame Press, 1974.

PARSONS, T. "The Traditional Square of Opposition". In: ZALTA, E.N. (ed.). The Stanford Encyclopedia of Philosophy (Summer 2017 Edition). Disponível em https://plato.stanford.edu/archives/sum2017/entries/square/. Acesso em: 20 set. 2020.

PRIEST, G. "On Alternative Geometries, Arithmetics, and Logics: a Tribute to Łukasiewicz". Studia Logica, 74, 2003, pp. 441-468.

PRIOR, A. N. Formal Logic. Oxford: Oxford University Press, 1962.

The Doctrine of Propositions and Terms. London: Duckworth,

1976.

READ, S. "Aristotle and Łukasiewicz on Existential Import". Journal of the American Philosophical Association, Vol. 1, №3, 2015, pp. 535-44.

RESCHER, N. Al-Farabi's Short Commentary on Aristotle's Prior Analytics. Pittsburgh: University of Pittsburgh Press, 1963.

ROSE, L. E. Aristotle's Syllogistic. Illinois: Charles C. Thomas, 1968.

SMITH, R. "Aristotle's Logic". In: ZALTA, E. N. (ed.). The Stanford Encyclopedia of Philosophy (Summer 2019 Edition). Disponível em:

https://plato.stanford.edu/archives/sum2019/entries/aristotle-logic/. Acesso em: 20 set. 2020 .

VALENCIA, V. S. "The Algebra of Logic". In: GABBAY, D. M.; WOODS, J. H. (eds.). Handbook of the History of Logic. Rise of Modern Logic: From Leibniz to Frege. Amsterdam: North-Holland, 2004, pp. 389-544.

WEDIN, M. V. "Aristotle on the existential import of singular sentences". Phronesis, 23, 1978, pp. 179-196.

. "Negation and Quantification in Aristotle". History and Philosophy of Logic, 11:2, 1990, pp. 131-150. 
Perspectiva Filosófica, vol. 47, n. 2, 2020

WU, J. S. "The Problem of Existential Import (From George Boole to P. F. Strawson)". Notre Dame Journal of Formal Logic, vol. X, n. 4, 1969, pp. 415424. 